\title{
STUDY ON ALCOHOL AND ITS NEUROLOGICAL COMPLICATIONS
}

\author{
Akumnaro Jamir' ${ }^{1}$, A. Ramalingam², G. Vasumathi', S. M. Sujatha ${ }^{4}$ \\ ${ }_{1}^{1}$ Post Graduate, Department of General Medicine, Stanley Medical College, Chennai. \\ ${ }^{2}$ Senior Assistant Professor, Department of General Medicine, Stanley Medical College, Chennai. \\ 3Professor, Department of General Medicine, Stanley Medical College, Chennai. \\ ${ }^{4}$ Senior Assistant Professor, Department of General Medicine, Stanley Medical College, Chennai.
}

\begin{abstract}
BACKGROUND

Alcoholism is characterised by alcohol tolerance, signs and symptoms of withdrawal and continued use in spite of insidious physical or psychological consequences. Chronic alcohol abuse causes several distinct diseases affecting many organs; however, the alcohol affecting the brain is the most significant factor for maintaining this alcohol abuse. The neurological complications of alcoholism include both the peripheral and the central nervous system like the alcohol withdrawal syndrome which includes alcohol withdrawal seizures, delirium tremens, alcohol hallucinosis. The other neurological complications are the alcoholic peripheral neuropathy, alcoholic myopathy, Wernicke encephalopathy, combination of Wernicke encephalopathy with Korsakoff's psychosis. Not all alcoholics are alike. The degree of impairment differs from individual to individual and the aetiology of a particular disease has different origins for different people. In the current scenario, it is still a subject of active research as to what characteristic features makes certain group of alcoholics more vulnerable to brain damage.
\end{abstract}

\section{MATERIALS AND METHODS}

The present study was undertaken under the Department of General Medicine, Govt. Stanley Hospital, Chennai. The study consists of 150 patients with history of alcohol intake satisfying the inclusion and exclusion criteria, presenting in medical OPD/wards/ICU, after proper consent were subjected to questionnaires, complete physical examination and relevant laboratory investigations as per proforma. A prospective observational study design was chosen and descriptive statistics was done for all data and suitable statistical tests of comparison for a period of 6 months.

\section{RESULTS}

It was found that alcohol withdrawal seizures and acute hallucinosis were the most common neurological sequelae seen. Acute hallucinosis was more prevalent in younger age group, whereas complications like alcohol polyneuropathy, Wernicke's-Korsakoff syndrome were found to be associated with older age group and with longer duration and higher quantity of alcohol intake. The age of onset of consumption of alcohol for majority of the participants was around 26-30 years of age.

\section{CONCLUSION}

This study contributes in the daily practice of clinicians, when encountering patients with chronic alcohol abuse to identify and differentiate the neurological complications of chronic alcoholism and at the same time understand its pathophysiology so that this treatment can be tailored to individual patients.

\section{KEYWORDS}

Alcoholism, Neurological Complications.

HOW TO CITE THIS ARTICLE: Jamir A, Ramalingam A, Vasumathi G, et al. Study on alcohol and its neurological complications. J. Evolution Med. Dent. Sci. 2016;5(54):3662-3666, DOI: 10.14260/jemds/2016/843

\section{INTRODUCTION}

Alcoholism is characterised by alcohol tolerance, signs and symptoms of withdrawal and continued use in spite of insidious physical or psychological consequences. Recent diagnostic criteria define Alcohol Use Disorder by the presence of at least 2 out of the given conditions for more than a yeartolerance, signs and symptoms of alcohol withdrawal, drinking in excessive amount, a strong desire to use alcohol, unsuccessful efforts to reduce drinking, spending more time in alcohol and alcohol related activity, affecting one's personal

Financial or Other, Competing Interest: None.

Submission 01-06-2016, Peer Review 27-06-2016,

Acceptance 02-07-2016, Published 07-07-2016.

Corresponding Author:

Dr. Akumnaro Jamir,

Ladies PG Hostel, Room No. 108,

Stanley Medical College,

Chennai-600001.

E-mail: kumti.jamir@yahoo.com

DOI: $10.14260 /$ jemds/2016/843 work and social lifestyle due to alcohol, continuous alcohol use despite persistent social, interpersonal problems, alcohol use in spite of persistent recurrent physical and psychological consequences (DSM-5, 2013). Chronic alcohol abuse causes several distinct diseases affecting many organs including the liver, lung, stomach and the brain. However, the alcohol affecting the brain is the most significant factor for maintaining this alcohol abuse. These effects include emotional and behavioural changes as well as defective judgement, learning disability and memory dysfunction. Studies have shown that radio-imaging studies have documented presence of damage in the brain of alcoholics like shrinkage of the brain and atrophy of the nerve cells. At the basic cellular level, alcohol affects the functioning of the brain by affecting the gammaaminobutyric acid, glutamate and other neurotransmitters. ${ }^{(1)}$ The neurological complications of alcoholism includes both the peripheral and the central nervous system. 
They are the alcohol withdrawal syndrome which includes alcohol withdrawal seizures, delirium tremens, alcohol hallucinosis.

The other neurological complications are the alcoholic peripheral neuropathy, alcoholic myopathy, Wernicke encephalopathy, combination of Wernicke encephalopathy with Korsakoff's psychosis.(1) Besides these complications less common complications have been identified which includes Marchiafava-Bignami Syndrome, subacute encephalopathy with seizure activity (SESA Syndrome), alcohol cerebellar degeneration which are usually diagnosed by their characteristic MRI and EEG findings.(2)

\section{Incidences and Prevalence in India}

According to the WHO 2014, global status report on alcohol and health, $38.3 \%$ of the total world population consumes alcohol and $30 \%$ of the total population in India.(3) The prevalence of alcohol dependence is $12.5 \%$ and the prevalence of alcohol abuse is $17.8 \%$ in a lifetime.(3) The per capita consumption of alcohol globally is 6.6 litres, in India it is 2.2 litres. Around 200 different health conditions covered by the ICD-10 is associated with alcohol consumption. Out of which 3.3 million deaths are attributed to alcohol globally.(3) These statistical data encourages and contributes towards the importance of further researches in alcoholism and its underlying mechanism.

\section{AIMS AND OBJECTIVES}

1. To study the prevalence of various neurological related complications in alcoholism.

2. To study the correlation of duration and quantity of alcohol intake leading to neurological complications.

\section{MATERIALS AND METHODS}

The present study was undertaken under the Department of General Medicine, Govt. Stanley Hospital, Chennai. The study consists of 150 patients with history of alcohol intake satisfying the inclusion and exclusion criteria, presenting in medical OPD/wards/ICU, after proper consent were subjected to questionnaires, complete physical examination and relevant laboratory investigations as per proforma. A prospective observational study design was chosen and descriptive statistics was done for all data and suitable statistical tests of comparison for a period of 6 months.

\section{Inclusion Criteria}

Patients with history of alcoholism.

\section{Exclusion Criteria}

1. Patients with Chronic liver disease/Hepatic Encephalopathy.

2. Patients with known Seizure disorder.

3. Patients with Diabetes Mellitus.

4. Patients with Psychiatric illness.

5. Patients with Congenital disease.

6. Patients with Cerebrovascular accidents.

7. Patients with acute CNS infections.

Study Duration: Jan. 2015 to Sept. 2015

Study Design: Prospective Observational Study.

Sample Size: 150

\section{Data Collection}

This study is an observational prospective study, wherein 150 alcoholic patients satisfying inclusion and exclusion criteria were subjected to answer a set of questionnaires, complete physical examination and relevant laboratory investigations as per proforma, exclusively designed for the study. Prior permission from Institutional Ethics Committee was taken, written/informed consent from every subject was taken.

\section{Statistics}

Descriptive statistics was done for all data and were reported in terms of whole observed values and percentages. Suitable statistical tests of comparison were done. Categorical variables were analysed with the Chi-Square Test. Statistical significance was taken as $\mathrm{P}<0.05$. The data was analysed using SPSS version 16 and Microsoft Excel 2007.

\section{Alcoholism Definition}

National Council on Alcoholism and Drug Dependence and the American Society of Addiction Medicine defines alcoholism as a primary, chronic disease characterized by impaired control over thinking, pre-occupation with the drug alcohol, use of alcohol despite adverse consequences and distortions in thinking. DSM-IV defines alcoholism as maladaptive alcohol use with clinically significant impairment.

\section{RESULTS}

\section{Neurological Complications in Alcoholics}

In our study patients, alcohol withdrawal seizures (38\%) was the most common neurological complication followed by acute hallucinosis (20\%). Alcoholic myopathy (2\%) and WernickeKorsakoff syndrome (8\%) were the least common neurological complications seen.

\section{Age Distribution}

Study showed that in 26-35 yrs., acute hallucinosis (35\%) was more prevalent. In 36-55 yrs., alcohol withdrawal seizures (46\%) was more prevalent, whereas in 56-65 yrs. alcohol polyneuropathy $(21 \%)$ was more prevalent. The study also concluded that the incidence of alcohol hallucinosis was significantly and consistently higher in younger age group patients and the incidence of alcoholic polyneuropathy, Wernicke's encephalopathy, Wernicke's-Korsakoff syndrome were significantly and consistently higher in very older age group patients.

\section{Gender Distribution}

The alcohol intake and its associated neurological complications were found to be more prevalent among the males (90\%) as compared to females and transgender. There was a contribution of $5 \%$ of female alcoholics and $4 \%$ of transgender alcoholics in the study group.

\section{Brand of Alcohol}

It was observed that brandy (29\%) was the most common brand of alcohol used among the study group followed by whiskey (22\%). Of the brands, wine (2\%) and country liquor were the least commonly used.

\section{Duration of Alcohol Intake}

It was found in the study that alcohol withdrawal seizure was the most common neurological complication seen except in the 
group with history of alcohol intake for a duration 0-5 years, alcohol hallucinosis was more prevalent.

The study also concluded that incidence of alcohol hallucinosis was significantly and consistently higher in patients with lesser duration of alcohol intake, whereas the incidence of alcoholic polyneuropathy and WernickeKorsakoff encephalopathy was significantly and consistently higher in patients with longer duration of alcohol intake.

\section{Quantity of Alcohol Intake}

The participants taking alcohol of around $840 \mathrm{gm} /$ week had alcohol hallucinosis more common as a neurological complication, whereas the prevalence of alcohol hallucinosis and alcohol withdrawal seizure was equally seen in participants with alcohol intake of around 770 gm/week. For the rest of the group alcohol withdrawal seizure was the most common neurological complication. The study also concluded that the incidence of alcohol hallucinosis, Wernicke's encephalopathy and Wernicke-Korsakoff syndrome was significantly and consistently higher in patients with higher quantity of alcohol intake. The incidence of alcoholic polyneuropathy was significantly and consistently higher in patients with lower quantity of alcohol intake.

\section{Age of Onset of Alcohol Consumption}

In our study, it was found that the maximum age of onset of alcohol consumption was between 26-30 years of age.

\section{DISCUSSION}

Excessive indulgence of an individual in alcohol causes many problems and chaos at the individual level as well as at the society level. The chronic effects of alcohol abuse include neurological complications through both direct and indirect effects on the central and peripheral nervous system. These complications include alcohol withdrawal syndrome in the form of delirium tremens which is characterized by a state of intense acute withdrawal state in the form of mental confusion, diaphoresis, agitation, fluctuating levels of consciousness, visual and auditory hallucinations associated with tremors and autonomic activity.(4) Alcohol withdrawal seizures occur within 48 hours of alcohol cessation and occur either as a single generalized tonic-clonic seizure or a brief episode of multiple seizures usually with a normal EEG record.(5) In alcohol hallucinosis the patients have transient visual, auditory or tactile hallucination, but are otherwise clear. Principally Wernicke's encephalopathy is a nutrition deficiency disorder due to brain damage caused by lack of thiamine, most frequently seen in chronic alcoholic patients characterised by a triad of mental confusion, ataxia and ophthalmoplegia. Wernicke-Korsakoff Syndrome includes symptoms of Wernicke's encephalopathy along with global amnesia, which includes both retrograde and anterograde amnesia and confabulation.(6) Here, MRI findings may show hyperintense T2 lesions in mammillary bodies, medial thalami, tectal plate, periaqueductal area. Alcohol polyneuropathy is characterised by axonal degeneration and demyelination. Symptoms include paraesthesias, pain and weakness, reduced pain and temperature sensations confirmed by nerve conduction study. In alcohol myopathy, the main complaints include muscle pain, severe cramps in the muscles, weakness of limbs, mostly the proximal muscles and associated swelling of muscles and tenderness. Chronic alcoholic myopathy is characterized by a gradual long-term involvement of the muscles, which are usually painless and involves the weakness of the proximal muscles with associated muscle atrophy.

\section{CONCLUSION}

Not all alcoholics are alike. The degree of impairment differs from individual to individual and the aetiology of a particular disease has different origins for different people. With the known existing harmful nature of alcoholism in the society, its complications have been already recognised clinically for years, hence the current recent advances are emphasizing more in understanding the biochemical targets of ethanol and the pathophysiology of the complications. In current scenario, it is still a subject of active research as to what characteristic features makes certain group of alcoholics more vulnerable to brain damage. This study contributes to daily practice when encountering patients with chronic alcohol abuse to identify and differentiate the neurological complications of chronic alcoholism and at the same time understand its pathophysiology so that these treatments can be tailored to individual patients. Also to encourage further researches on advanced technology, to design newer therapies and medicines for diagnosis and to ameliorate alcoholism and alcohol related neurological disorder.

\section{STATISTICS}

\begin{tabular}{|c|c|c|}
\hline $\begin{array}{l}\text { Neurological } \\
\text { Complications } \\
\text { in Alcoholics }\end{array}$ & Number & Percentage \\
\hline Alcohol Withdrawal Seizures & 57 & 38.00 \\
\hline Delirium Tremens & 28 & 18.67 \\
\hline Alcohol Hallucinosis & 30 & 20.00 \\
\hline Alcoholic Polyneuropathy & 14 & 9.33 \\
\hline Alcoholic Myopathy & 4 & 2.67 \\
\hline Wernicke Encephalopathy & 9 & 6.00 \\
\hline $\begin{array}{l}\text { Wernicke-Korsakoff } \\
\text { Encephalopathy }\end{array}$ & 8 & 5.33 \\
\hline Total & 150 & 100 \\
\hline \multicolumn{3}{|c|}{$\begin{array}{l}\text { Table 1: The Percentage of Neurological } \\
\text { Complications in Alcoholics }\end{array}$} \\
\hline
\end{tabular}




\begin{tabular}{|c|c|c|c|c|c|c|c|c|c|}
\hline $\begin{array}{l}\text { Neurological Complications in } \\
\text { Alcoholics-Age Distribution }\end{array}$ & 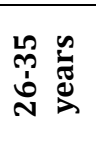 & de & 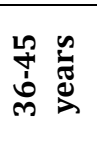 & $\partial^{0}$ & 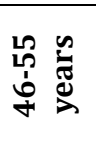 & $a^{e}$ & 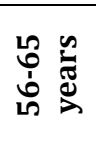 & $a^{e}$ & 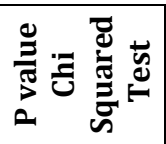 \\
\hline Alcohol Withdrawal Seizures & 12 & 28.57 & 30 & 46.88 & 10 & 33.33 & 5 & 35.71 & 0.258 \\
\hline Delirium Tremens & 11 & 26.19 & 14 & 21.88 & 3 & 10.00 & 0 & 0.00 & 0.082 \\
\hline Alcohol Hallucinosis & 15 & 35.71 & 13 & 20.31 & 0 & 0.00 & 2 & 14.29 & 0.003 \\
\hline Alcoholic Polyneuropathy & 2 & 4.76 & 3 & 4.69 & 6 & 20.00 & 3 & 21.43 & 0.028 \\
\hline Alcoholic Myopathy & 2 & 4.76 & 2 & 3.13 & 0 & 0.00 & 0 & 0.00 & 0.579 \\
\hline Wernicke Encephalopathy & 0 & 0.00 & 1 & 1.56 & 6 & 20.00 & 2 & 14.29 & 0.001 \\
\hline Wernicke-Korsakoff Encephalopathy & 0 & 0.00 & 1 & 1.56 & 5 & 16.67 & 2 & 14.29 & 0.003 \\
\hline Total & 42 & 100 & 64 & 100 & 30 & 100 & 14 & 100 & \\
\hline
\end{tabular}

\begin{tabular}{|c|c|c|c|c|c|c|c|}
\hline $\begin{array}{c}\text { Neurological Complications } \\
\text { in Alcoholics-Gender Distribution }\end{array}$ & Male & $\mathbf{\%}$ & Female & $\mathbf{\%}$ & Transgender & $\begin{array}{c}\text { \% value } \\
\text { Chi Squared Test }\end{array}$ \\
\hline Alcohol Withdrawal Seizures & 53 & 38.97 & 3 & 37.50 & 1 & 16.67 & 0.545 \\
\hline Delirium Tremens & 28 & 20.59 & 0 & 0.00 & 0 & 0.00 & 0.17 \\
\hline Alcohol Hallucinosis & 27 & 19.85 & 0 & 0.00 & 3 & 50.00 & 0.068 \\
\hline Alcoholic Polyneuropathy & 12 & 8.82 & 1 & 12.50 & 1 & 16.67 & 0.772 \\
\hline Alcoholic Myopathy & 4 & 2.94 & 0 & 0.00 & 0 & 0.00 & 0.804 \\
\hline Wernicke Encephalopathy & 6 & 4.41 & 2 & 25.00 & 1 & 16.67 & 0.033 \\
\hline Wernicke-Korsakoff Encephalopathy & 6 & 4.41 & 2 & 25.00 & 0 & 0.00 & 0.037 \\
\hline
\end{tabular}

\begin{tabular}{|c|c|c|}
\hline Brand of Alcohol Used & Number & Percentage \\
\hline Beer & 28 & 18.67 \\
\hline Wine & 3 & 2.00 \\
\hline Whiskey & 34 & 22.67 \\
\hline Brandy & 44 & 16.67 \\
\hline Rum & 25 & 6.00 \\
\hline Vodka & 9 & 0.00 \\
\hline Country Liquor & 7 & $\mathbf{9 5}$ \\
\hline Total Table 4: The Percentage of Brand of Alcohol Used in Alcoholics \\
\hline
\end{tabular}

\begin{tabular}{|c|c|c|c|c|c|c|c|c|c|c|c|}
\hline $\begin{array}{c}\text { Neurological } \\
\text { Complications in } \\
\text { Alcoholics Vs Duration of } \\
\text { Intake }\end{array}$ & $\begin{array}{c}0-5 \\
\text { years }\end{array}$ & $\%$ & $\begin{array}{c}6-10 \\
\text { years }\end{array}$ & $\%$ & $\begin{array}{l}11-15 \\
\text { years }\end{array}$ & $\%$ & $\begin{array}{l}16-20 \\
\text { years }\end{array}$ & $\%$ & $\begin{array}{l}21-25 \\
\text { years }\end{array}$ & $\%$ & $\begin{array}{c}\text { P value } \\
\text { Chi Squared } \\
\text { Test }\end{array}$ \\
\hline $\begin{array}{c}\text { Alcohol Withdrawal } \\
\text { Seizures }\end{array}$ & 13 & 33.33 & 15 & 30.61 & 19 & 52.78 & 6 & 30.00 & 4 & 66.67 & 0.103 \\
\hline Delirium Tremens & 8 & 20.51 & 13 & 26.53 & 7 & 19.44 & 0 & 0.00 & 0 & 0.00 & 0.087 \\
\hline Alcohol Hallucinosis & 15 & 38.46 & 11 & 22.45 & 1 & 2.78 & 3 & 15.00 & 0 & 0.00 & 0.003 \\
\hline Alcoholic Polyneuropathy & 0 & 0.00 & 4 & 8.16 & 4 & 11.11 & 5 & 25.00 & 1 & 16.67 & 0.034 \\
\hline Alcoholic Myopathy & 1 & 2.56 & 3 & 6.12 & 0 & 0.00 & 0 & 0.00 & 0 & 0.00 & 0.412 \\
\hline Wernicke Encephalopathy & 2 & 5.13 & 1 & 2.04 & 4 & 11.11 & 2 & 10.00 & 0 & 0.00 & 0.402 \\
\hline $\begin{array}{c}\text { Wernicke-Korsakoff } \\
\text { Encephalopathy }\end{array}$ & 0 & 0.00 & 2 & 4.08 & 1 & 2.78 & 4 & 20.00 & 1 & 16.67 & 0.012 \\
\hline Total & 39 & 100 & 49 & 100 & 36 & 100 & 20 & 100 & 6 & 100 & \\
\hline
\end{tabular}

\begin{tabular}{|c|c|c|c|c|c|c|c|c|}
\hline $\begin{array}{l}\text { Neurological Complications } \\
\text { in Alcoholics Vs Quantity of } \\
\text { Intake }\end{array}$ & $\begin{array}{c}490 \\
\text { g/week }\end{array}$ & $\%$ & $\begin{array}{c}560 \\
\text { g/we } \\
\text { ek }\end{array}$ & $\%$ & $\begin{array}{c}630 \\
\text { g/week }\end{array}$ & $\%$ & $\begin{array}{c}700 \\
\text { g/week }\end{array}$ & $\%$ \\
\hline Alcohol Withdrawal Seizures & 7 & 43.75 & 8 & 33.33 & 16 & 39.02 & 15 & 44.12 \\
\hline Delirium Tremens & 2 & 12.50 & 2 & 8.33 & 7 & 17.07 & 10 & 29.41 \\
\hline Alcohol Hallucinosis & 4 & 25.00 & 3 & 12.50 & 5 & 12.20 & 5 & 14.71 \\
\hline Alcoholic Polyneuropathy & 0 & 0.00 & 5 & 20.83 & 4 & 9.76 & 3 & 8.82 \\
\hline Alcoholic Myopathy & 1 & 6.25 & 0 & 0.00 & 2 & 4.88 & 1 & 2.94 \\
\hline Wernicke Encephalopathy & 1 & 6.25 & 4 & 16.67 & 4 & 9.76 & 0 & 0.00 \\
\hline $\begin{array}{c}\text { Wernicke-Korsakoff } \\
\text { Encephalopathy }\end{array}$ & 1 & 6.25 & 2 & 8.33 & 3 & 7.32 & 0 & 0.00 \\
\hline Total & 16 & 100 & 24 & 100 & 41 & 100 & 34 & 100 \\
\hline
\end{tabular}




\begin{tabular}{|c|c|c|c|c|c|c|c|}
\hline $\begin{array}{c}\text { Neurological Complications } \\
\text { in Alcoholics Vs Quantity of Intake }\end{array}$ & $\begin{array}{c}\mathbf{7 7 0} \\
\text { g/week }\end{array}$ & $\mathbf{\%}$ & $\begin{array}{c}\mathbf{8 4 0} \\
\text { g/week }\end{array}$ & $\mathbf{\%}$ & $\begin{array}{c}\mathbf{9 1 0} \\
\text { g/week }\end{array}$ & $\mathbf{\%}$ & $\begin{array}{c}\text { P value } \\
\text { Chi Squared Test }\end{array}$ \\
\hline Alcohol Withdrawal Seizures & 6 & 33.33 & 5 & 29.41 & 4 & 44.44 & 0.302 \\
\hline Delirium Tremens & 5 & 27.78 & 2 & 11.76 & 0 & 0.00 & 0.113 \\
\hline Alcohol Hallucinosis & 6 & 33.33 & 7 & 41.18 & 3 & 33.33 & 0.025 \\
\hline Alcoholic Polyneuropathy & 1 & 5.56 & 1 & 5.88 & 0 & 0.00 & 0.017 \\
\hline Alcoholic Myopathy & 0 & 0.00 & 0 & 0.00 & 1 & 11.11 & 0.598 \\
\hline Wernicke Encephalopathy & 0 & 0.00 & 0 & 0.00 & 1 & 11.11 & 0.045 \\
\hline Wernicke-Korsakoff Encephalopathy & 0 & 0.00 & 2 & 11.76 & 0 & 0.00 & 0.017 \\
\hline
\end{tabular}

\begin{tabular}{|c|c|c|}
\hline Age of Onset of Alcohol Consumption & No. & $\mathbf{\%}$ \\
\hline$\leq 20$ years & 1 & 0.67 \\
\hline $21-25$ years & 46 & 30.67 \\
\hline $26-30$ years & 83 & 55.33 \\
\hline $31-40$ years & 19 & 12.67 \\
\hline 41-50 years & 1 & 0.67 \\
\hline Total & $\mathbf{1 5 0}$ & $\mathbf{1 0 0}$ \\
\hline Table 8: Distribution ofthe Age of Onset \\
of Alcohol Consumption \\
\hline
\end{tabular}

\section{REFERENCES}

1. In: Hunt WA, Nixon SJ, eds. Alcohol-induced brain damage. National institute on alcohol abuse and alcoholism research monograph no. 22.NIH Pub. No 933549. Bethseda, MD: the Institute 1993:121-156.
2. Evert DL, Berman OM. Alcohol-related cognitive impairments: an overview of how alcoholism may affect the workings of the brain. Alcohol Health \& Research World 1995;19(2):89-96

3. Global status report on alcohol and heath. World Health Organisation 2014.

4. Alcohol and alcoholism. In: Ropper AH, Samuels MA, Klein J. Adams \& Victor's principles of neurology. Chapter 42, $10^{\text {th }}$ edn. McGraw Hill Professional 2014:pgs. 1584.

5. Alcoholism, alcohol withdrawal syndrome. Kasper DJ, Jameson L, Hauser S. Harrisons principle of internal medicine. Vol. 1 \& Vol. 2. 19th edn. McGraw-Hill Education 2015:pgs. 3000.

6. Victor M, Adams RD, Collins GH. The Wernicke-Korsakoff Syndrome. $2^{\text {nd }}$ edn. Philadelphia: Davis 1989. 